\title{
Popliteal Pterygium Syndrome
}

National Cancer Institute

\section{Source}

National Cancer Institute. Popliteal Pterygium Syndrome. NCI Thesaurus. Code C118786.

A rare, autosomal dominant inherited syndrome caused by mutations in the IRF6 gene. It is characterized by the presence of cleft palate, cleft lip, pits in the lower lip, web behind the knee (popliteal pterygium), syndactyly, cryptorchidism, scrotal malformation, and hypoplasia of the labia majora. 